\title{
Factors associated with periventricular haemorrhage in very low birthweight infants
}

\author{
RICHARD W I COOKE \\ Sophia Children's Hospital and Neonatal Unit, Rotterdam
}

SUMMARY Periventricular haemorrhage was diagnosed in vivo in 20 of 39 consecutively admitted infants of birthweight below $1500 \mathrm{~g}$ using an ultrasound scanner. Ten $(51 \%)$ infants with haemorrhages survived. Mortality was related to the extent of the bleeding. Statistically significant associations with respiratory distress, ventilator therapy, metabolic acidosis, and hypercapnia were observed, lending support to their role in the pathogenesis of periventricular haemorrhage.

Periventricular haemorrhage (PVH) is a common cause of death in infants of very low birthweights. Clinical diagnosis is often difficult, and most studies concerning pathogenesis of PVH have been of cases diagnosed at necropsy. The introduction of computerised tomography (CT) scans has allowed in vivo diagnosis of PVH to be made, and has shown a much higher incidence than had been expected. ${ }^{12}$ Two-dimensional ultrasound scanning has also been used successfully to visualise $\mathrm{PVH}$ in vivo. ${ }^{3} 4$ Portability of the equipment and lack of ionising radiation, make this method ideal for studying newborn infants in an intensive care unit.

Previous studies of factors associated with $\mathrm{PVH}$ in low birthweight infants have used clinical diagnosis or examination at necropsy to define a 'haemorrhage group' which was then compared with a remaining 'non-haemorrhage' group. ${ }^{1617}$ As the nonhaemorrhage group will inevitably contain some infants with non-fatal haemorrhages, such a comparison may fail to demonstrate differences. In the present study diagnosis of PVH was made using an ultrasound sector scanner. Infants with PVH were then compared with infants in whom no bleeding was detected.

\section{Methods}

Thirty-nine preterm infants weighing $<1500 \mathrm{~g}$ at birth, and consecutively admitted to the neonatal unit at this hospital, were studied. Data concerning birthweight, birth order, method of delivery, gestation, and need for resuscitation at birth were recorded. Each day after admittance the occurrence of respiratory disease, pneumothorax, convulsions, or sudden deteriorations was noted, together with details of ventilatory support and inspired oxygen administered. Blood gas data were recorded as the lowest oxygen saturation $\left(\mathrm{So}_{2}\right)$, lowest $\mathrm{pH}$, highest $\mathrm{PCO}_{2}$, and lowest base excess measured each day. Up to 8 blood gas measurements determined on arterial or arterialised capillary blood were made each day depending on clinical need. No measurements were made for the purpose of this study. A daily haematocrit was also recorded.

The first ultrasound scan was made between the 5th and 10th day of life in infants who did not have clinical signs that suggested PVH. If a clinical diagnosis of haemorrhage was made before age 5 days, an earlier scan was made. If a PVH was seen, regular follow-up scans were made until the infant was discharged home, or died. CT scans were performed too on some infants with clinical evidence of PVH at the discretion of the managing paediatrician.

Ultrasound scans were made using an Advanced Technology Labs 850 A sector scanner with a 3.5 or $5 \mathrm{MHz}$ head. Scans were made through the fontanelle in both a right and left parasagittal position and coronally, when the scan plane was 'swept' from an anterior to posterior position. Scans were recorded in real-time on videotape, and photographed from a monitor screen on play-back. This technique has several advantages when compared with CT scans and other ultrasound techniques. Firstly the infant remains undisturbed in his incubator and the entire examination lasts 2 or 3 minutes. Secondly, by using the fontanelle as a 'window', and employing a sector type of ultrasound scanner rather than a linear array type, the bones of the skull are avoided, greatly increasing the quality of image. Theoretically, lateral resolution at the depth scanned is less than $2 \mathrm{~mm}$, and in practice germinal layer haemorrhages of 3-4 mm could be clearly distinguished. Thirdly, 
the ability to record 'sweeps' in real time on videotape, enables the images to be reviewed at leisure, and an almost infinite number of 'cuts' to be seen. A suspected haemorrhage can be viewed in 3 dimensions and distinguished from the other bright echoes in the region of the lateral ventricles originating from the fornix.

\section{Results}

Incidence and extent of PVH. Using the technique described it was possible to detect PVH in $20(51 \%)$ of the 39 infants. The haemorrhages were graded in a similar manner to that used by Papile et al. ${ }^{2}$ for CT scans of neonatal PVH: grade 1, confined to germinal layer or minimal intraventricular bleeding: grade 2, intraventricular haemorrhage; grade 3, intraventricular haemorrhage with ventricular distension; grade 4, parenchymal haemorrhage.

Fig. 1 shows a normal coronal and parasagittal
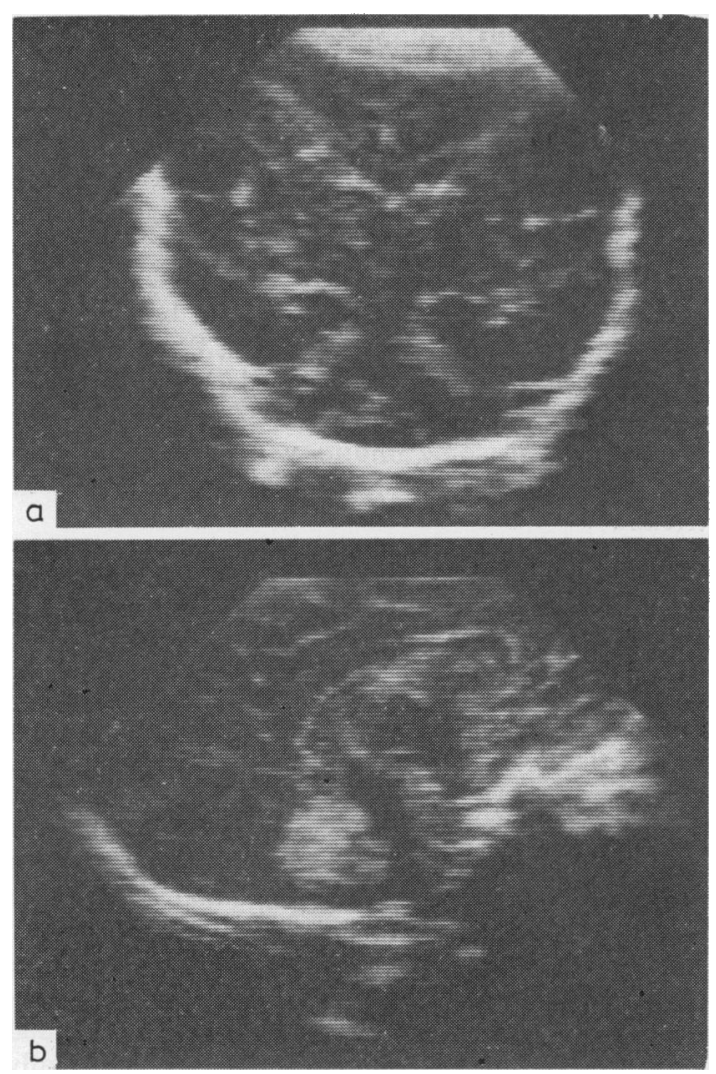

Fig. 1a Normal coronal section through fontanelle in a 900-g infant. (b) Normal parasagittal section through fontanelle in a 1200-g infant. scan; Fig. 2 shows the 4 grades of PVH as seen in coronal plane. Fig. 3 shows a parasagittal view of an intraventricular haemorrhage with a CT scan view taken on the same day.

Table 1 shows the distribution of grades, and rate of survival after $\mathrm{PVH}$.

Table 2 shows the birthweight, gestation, distribution of haemorrhage, and occurrence of ventricular dilatation after the PVH.

In all infants sustaining an intraventricular haemorrhage, and surviving the immediate incident, ventricular dilatation took place. Enlargement of the lateral ventricle was mainly in a vertical direction and towards the occiput (Fig. 4). Gross ventricular enlargement was present in 5 infants, 4 of whom died; 3 of them showed clinical hydrocephalus.

Of the 19 infants not sustaining PVH, 6 died: 4 of necrotising enterocolitis, 1 of respiratory causes, and 1 from Candida sp. and septicaemia, each of them after the first week of life.

Factors associated with PVH. Of the 39 infants examined, $20(51 \%)$ had evidence of PVH on ultrasound scan and were designated as the haemorrhage $(\mathrm{H})$ group. The remaining 19 infants formed the non-haemorrhage ( $\mathrm{NH})$ group. Clinical details and events relating to the two groups are shown in Table 3. The statistical differences between the groups have been determined by the Mann-Whitney U test or Fisher's exact test as appropriate. There was no statistically significant difference in gestational age, birthweight, the occurrence of premature rupture ( $>48$ hours) of amniotic membranes, mode of delivery, or the need for resuscitation at birth between the two groups. There was no significant difference in the recorded frequency of administration of hypertonic alkaline solutions at delivery. After admission to the unit only 2 infants received infusions of sodium bicarbonate, but each was known at the time to have had a PVH.

The $\mathrm{H}$ group had a higher incidence of respiratory distress $(P=0.0008)$ with a correspondingly higher incidence of respiratory support (CPAP or mechanical ventilation) on the first day of life $(P=0.0025)$ and during the first week $(P=0 \cdot 00045)$, Table 4 . There was however, no significant difference in the

Table 1 Survival after PVH according to grade of haemorrhage

\begin{tabular}{lll}
\hline Grade & Lived & Died \\
\hline $1(n=5)$ & 5 & 0 \\
$2(n=8)$ & 4 & 4 \\
$3(n=4)$ & 0 & 4 \\
$4(n=3)$ & 1 & 2 \\
\hline
\end{tabular}



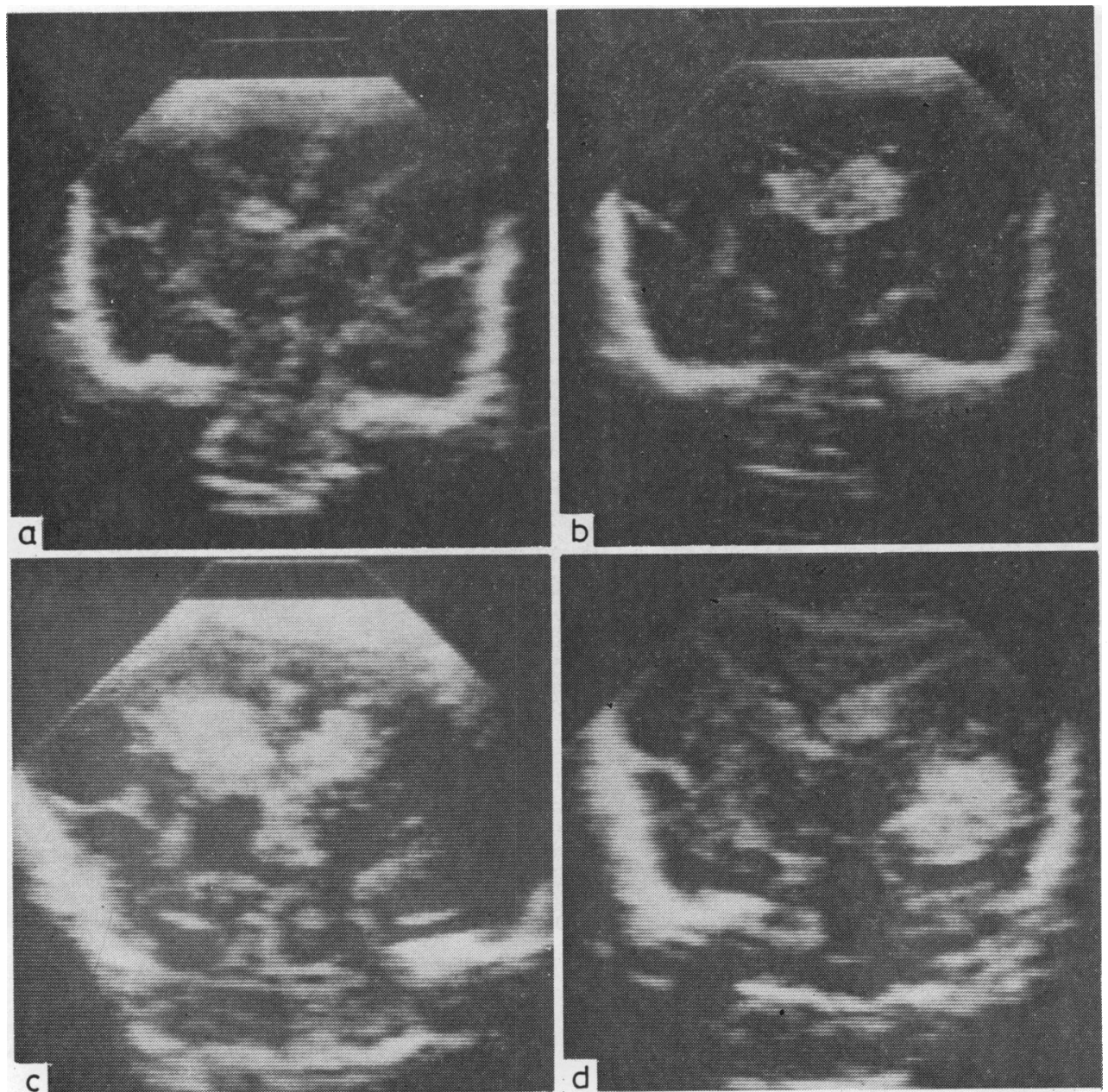

Fig. 2 Coronal sections: (a) grade 1, (b) grade 2, (c) grade 3, and (d) grade 4 PVH.

Table 2 Clinical data, type of $P V H$, and outcome for infants with PVH

\begin{tabular}{|c|c|c|c|c|c|}
\hline Grade & Birthweight $(g)$ & Gestation (weeks) & Extent of $P V H$ & Ventricular dilatation & Outcome \\
\hline \multirow[t]{5}{*}{1} & 960 & 29 & SEH/SEH & - & Lived \\
\hline & 1210 & 30 & SEH/SEH & 一 & Lived \\
\hline & 800 & 28 & $\mathrm{SEH} /-$ & - & Lived \\
\hline & 750 & 27 & SEH/- & + & Lived \\
\hline & 1460 & 32 & SEH/ - & - & Lived \\
\hline \multirow[t]{8}{*}{2} & 1130 & 28 & IVH/IVH & ++ & Died, 9 days \\
\hline & 1350 & 35 & IVH/IVH & ++ & Lived \\
\hline & 950 & 29 & IVH/IVH & + & Lived \\
\hline & 910 & 28 & IVH/SEH & + & Lived \\
\hline & 1250 & 30 & IVH/SEH & + & Died, 15 days \\
\hline & 1440 & 30 & IVH/IVH & + & Lived \\
\hline & 675 & 31 & IVH/IVH & - & Died, 2 days \\
\hline & 1210 & 30 & IVH/IVH & - & Died, 3 days \\
\hline \multirow[t]{4}{*}{3} & 1250 & 28 & IVH/IVH & ++ & Died, 8 days \\
\hline & 800 & 27 & IVH/SEH & ++ & Died, 9 days \\
\hline & 1330 & 30 & IVH/IVH & ++ & Died, 2 months \\
\hline & 970 & 28 & IVH/IVH & + & Died, 8 days \\
\hline \multirow{3}{*}{4} & 950 & 28 & IVH/IVH + parietal haematoma & - & Died, 3 days \\
\hline & 990 & 28 & IVH/IVH + parietal haematoma & - & Died, 4 days \\
\hline & 1000 & 32 & IVH $/$ - + frontal haematoma & + & Lived \\
\hline
\end{tabular}



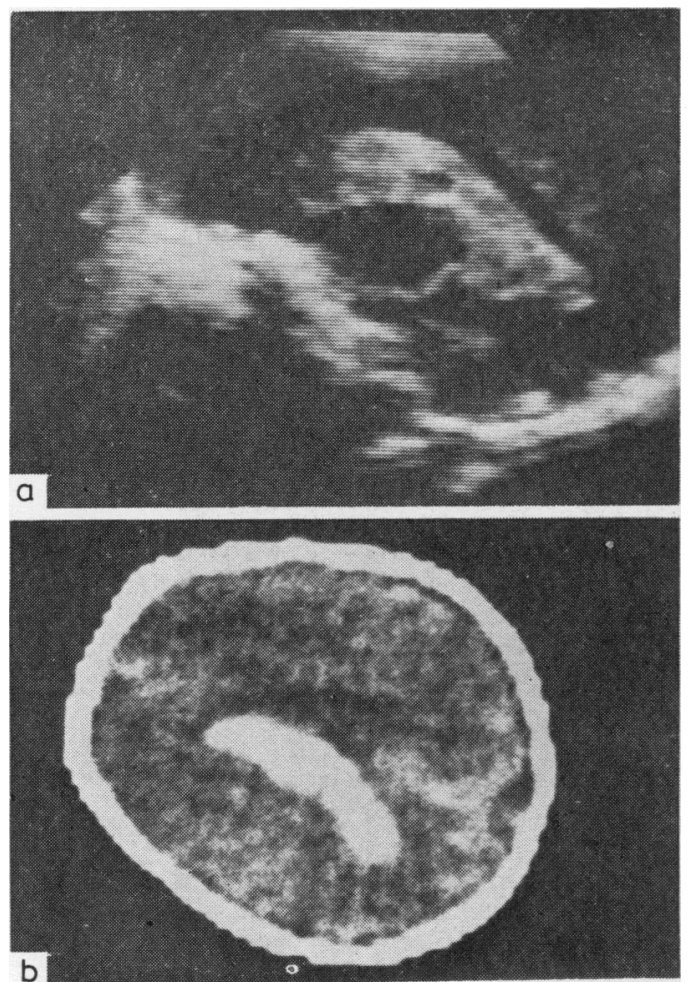

Fig. 3a Parasagittal section through lateral ventricle after IVH. (b) CT scan of same infant.

Table 3 Perinatal data on infants with and without evidence of $P V H$

\begin{tabular}{|c|c|c|c|}
\hline & $\begin{array}{l}\text { Haemorrhage } \\
\text { group } \\
(n=20)\end{array}$ & $\begin{array}{l}\text { Non-haemorrhage } \\
\text { group } \\
(n=19)\end{array}$ & $\boldsymbol{P}$ \\
\hline $\begin{array}{l}\text { Gestational age (weeks) } \\
\text { (median + range) }\end{array}$ & $\begin{array}{l}29 \\
(27-35)\end{array}$ & $\begin{array}{l}31 \\
(26-34)\end{array}$ & NS \\
\hline $\begin{array}{l}\text { Birthweight (g) } \\
\text { (median + range) }\end{array}$ & $\begin{array}{l}995 \\
(675-1460)\end{array}$ & $\begin{array}{l}1290 \\
(725-1500)\end{array}$ & NS \\
\hline $\begin{array}{l}\text { Male/female } \\
\text { Premature rupture of }\end{array}$ & $11 / 9$ & $9 / 10$ & \\
\hline membranes & 4 & 3 & NS \\
\hline $\begin{array}{l}\text { Mode of delivery, } \\
\text { caesarean section/ } \\
\text { vaginal }\end{array}$ & $5 / 15$ & $6 / 13$ & NS \\
\hline $\begin{array}{l}\text { Resuscitation at birth } \\
\text { Bicarbonate given at }\end{array}$ & 8 & 5 & NS \\
\hline $\begin{array}{l}\text { birth } \\
\text { Died }\end{array}$ & $\begin{array}{l}4 \\
10\end{array}$ & $\begin{array}{l}2 \\
6\end{array}$ & $\begin{array}{l}\text { NS } \\
\text { NS }\end{array}$ \\
\hline
\end{tabular}

incidence of pneumothorax or the need for inspired oxygen concentration of $>60 \%$ during the first week. Except in cases of massive haemorrhage, clinical signs and symptoms were often equivocal, and did not reliably predict PVH. A. fall in haematocrit in 24
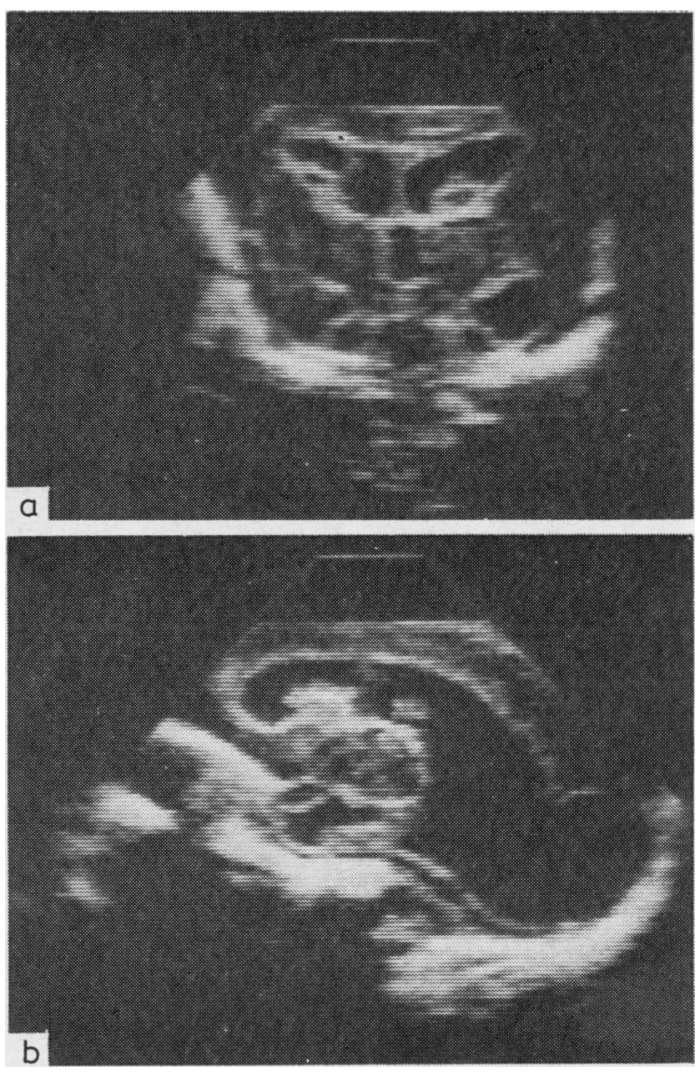

Fig. 4a Coronal section showing ventricular dilatation after IVH. (b) Parasagittal scan on same infant.

Table 4 Postnatal illness in infants with and without evidence of $P V H$

\begin{tabular}{|c|c|c|c|}
\hline & $\begin{array}{l}\text { Haemorrhage } \\
\text { group } \\
(n=20)\end{array}$ & $\begin{array}{l}\text { Non-haemorrhage } \\
\text { group } \\
(n=19)\end{array}$ & $P$ \\
\hline Respiratory distress & 17 & 6 & 0.0008 \\
\hline Severe recurrent apnoea & 3 & $\mathbf{0}$ & \\
\hline Pneumothorax & 4 & 1 & \\
\hline $\begin{array}{l}\text { Respiratory support } \\
\text { (CPAP/mechanical } \\
\text { ventilation) }\end{array}$ & & & \\
\hline 1st day & 16 & 6 & 0.0025 \\
\hline 1st week & 20 & 8 & 0.00045 \\
\hline $\begin{array}{l}\mathrm{F}_{1} \mathrm{O}_{2}>60 \% \text { ever } \\
\text { Haematocrit fell more }\end{array}$ & 8 & 3 & \\
\hline $\begin{array}{l}\text { Haematocrit fell more } \\
\text { than } 10 \text { points in } \\
24 \text { hours ever }\end{array}$ & 13 & 7 & 0.056 \\
\hline $\begin{array}{l}\text { Haematocrit fell more } \\
\text { than } 10 \text { points in } \\
24 \text { hours after first } \\
\text { day of life }\end{array}$ & 10 & 2 & 0.001 \\
\hline
\end{tabular}



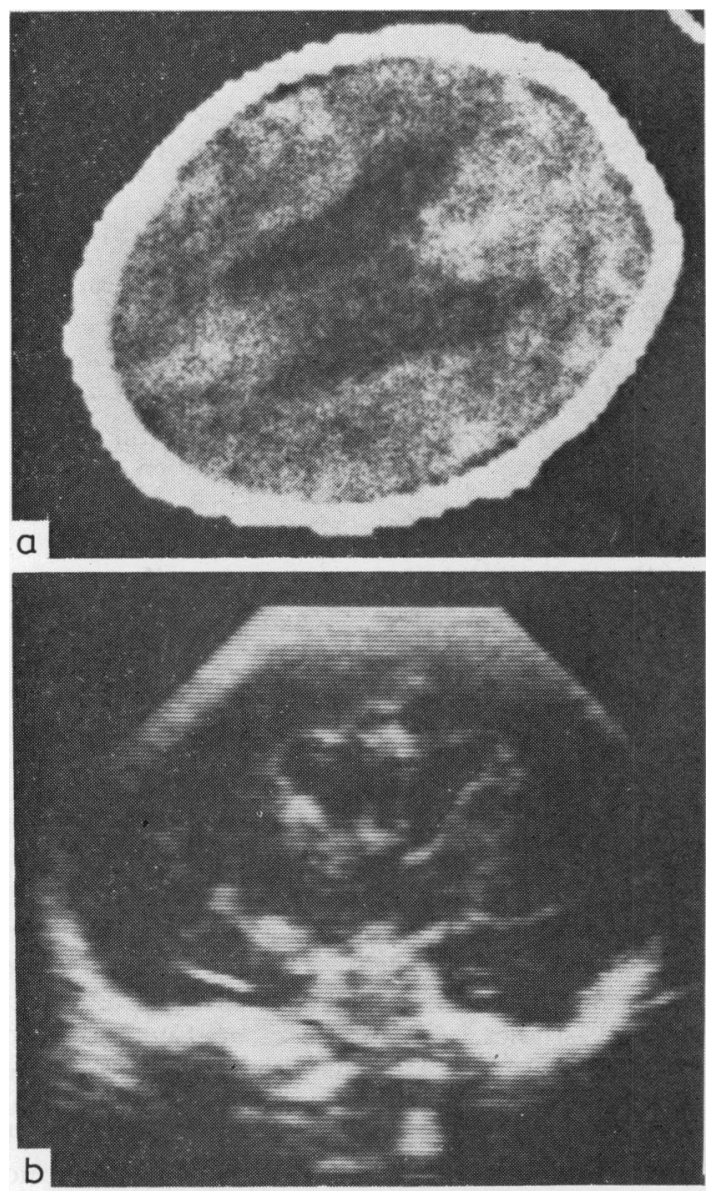

Fig. 5a CT scan 1 week after small IVH in 1200-g infant. (b) Coronal ultrasound scan on same day showing residual germinal layer haemorrhage not seen on CT.

hours of more than 10 points however, was associated with PVH if it occurred after the first day of life $(P=0.001)$.

Blood gas data for both groups on each of the first 7 days of life are summarised in Table 3. Medians and range for each variable are given, and the significance of differences tested non-parametrically using the Mann-Whitney U test.

Lower values for $\mathrm{So}_{2}$ in the $\mathrm{H}$ babies were seen, but the differences were not statistically significant. Infants in the $\mathbf{H}$ group had a significantly lower $\mathrm{pH}$ on the first 6 days of life. This was associated with a significantly lower base excess during the first 72 hours, and a significantly higher $\mathrm{PCO}_{2}$ during the first week.

\section{Discussion}

Recent in vivo diagnosis of PVH in very low birthweight infants using CT scans, showed a high incidence among surviving infants. ${ }^{2}$ If $\mathrm{PVH}$ in these infants has the same aetiology as in those who die, analysis of perinatal factors and events must be based on in vivo diagnosis rather than diagnosis at necropsy. Attempts at timing PVH have shown the highest incidence to be between 24 and 48 hours, indicating that early events are likely to be the most important. ${ }^{5}$ The use of a portable ultrasound scanner for diagnosis allowed examinations to be rapidly performed in the intensive care unit with little disturbance to the patient. Although a small pilot study has shown good comparability between ultrasound and CT scans, further comparisons within the study group were made in 7 infants on whom both forms of scan were performed on the same day. In all cases the grading was the same, although the differences in scan planes made the precise appearances differ. The resolution of the ultrasound scanner appeared rather better, as in the CT scan of a 1-week-old, 1200-g infant (Fig. 5a). A coronal scan by ultrasound, made at the same time (Fig. 5b), shows the same degree of ventricular dilatation but shows too the germinal layer haemorrhage which a few days earlier had caused a small IVH, not seen in the CT scan.

The incidence $(51 \%)$ of PVH in this study is similar to that in the study of Papile et al. ${ }^{2}(44 \%)$ in a similar group of infants. The distribution of the PVHs seen was also similar (Table 1). Mortality in grades $\mathbf{3}$ and $\mathbf{4}$ was much higher than in grades $\mathbf{1}$ and 2 and this was due mainly to the higher incidence of death at the time of the PVH or to the development of hydrocephalus later.

It is of interest to note that all infants with ventricular bleeding developed ventricular enlargement if they survived the initial incident, although this was not often clinically evident as hydrocephalus. In the survivors this enlargement reached a maximum at about 1 week after the event, and subsided slowly during the next 2 months, although 2 infants still had evidence of dilatation on discharge. The presence and degree of ventricular dilatation appears to be related to the presence and amount of blood released into the ventricular system, although dilatation was seen in 1 infant in whom only a germinal layer bleed was noted. Alternatively, it could be, at least in part, related to a degree of cerebral atrophy after hypoxia.

In the one long-term survivor of a grade 4 bleed, a large loculated cerebral cyst persisted at the site of the initial frontal lobe haematoma, and neurological examination at 3 months was abnormal. All other 
Table 5 Median values (with range) for extreme values of blood gas data in haemorrhage and non-haemorrhage infants during the first 7 days of life

\begin{tabular}{|c|c|c|c|c|c|c|c|}
\hline & \multicolumn{7}{|l|}{ Day } \\
\hline & $I$ & 2 & 3 & 4 & 5 & 6 & 7 \\
\hline $\begin{array}{l}\mathrm{So}_{2}(\%) \\
\text { Haemorrhage } \\
\text { Non-haemorrhage } \\
\mathrm{P}\end{array}$ & $\begin{array}{l}83 \\
(26-100) \\
89 \\
(44-100) \\
\text { NS }\end{array}$ & $\begin{array}{l}84 \\
(21-98) \\
92 \\
(80-100) \\
\text { NS }\end{array}$ & $\begin{array}{l}85 \\
(55-98) \\
93 \\
(84-100) \\
\text { NS }\end{array}$ & $\begin{array}{l}90 \\
(55-150) \\
95 \\
(49-100) \\
\text { NS }\end{array}$ & $\begin{array}{l}90 \\
(22-99) \\
94 \\
(85-100) \\
\text { NS }\end{array}$ & $\begin{array}{l}86 \\
(57-100) \\
94 \\
(68-97) \\
\text { NS }\end{array}$ & $\begin{array}{l}84 \\
(58-91) \\
90 \\
(42-100) \\
\text { NS }\end{array}$ \\
\hline $\begin{array}{l}\text { pH } \\
\text { Haemorrhage } \\
\text { Non-haemorrhage } \\
\text { P }\end{array}$ & $\begin{array}{l}7 \cdot 18 \\
(6 \cdot 92-7 \cdot 53) \\
7 \cdot 29 \\
(7 \cdot 13-7 \cdot 36) \\
<0 \cdot 05\end{array}$ & $\begin{array}{l}7 \cdot 15 \\
(6 \cdot 77-7 \cdot 39) \\
7 \cdot 32 \\
(7 \cdot 23-7 \cdot 40) \\
<0 \cdot 001\end{array}$ & $\begin{array}{l}7 \cdot 17 \\
(6 \cdot 93-7 \cdot 39) \\
7 \cdot 27 \\
(7 \cdot 01-7 \cdot 35) \\
<0 \cdot 001\end{array}$ & $\begin{array}{l}7 \cdot 21 \\
(7 \cdot 04-7 \cdot 37) \\
7 \cdot 27 \\
(7 \cdot 06-7 \cdot 38) \\
<0.05\end{array}$ & $\begin{array}{l}7 \cdot 20 \\
(7 \cdot 02-7 \cdot 39) \\
7 \cdot 26 \\
(7 \cdot 15-7 \cdot 38) \\
<0 \cdot 025\end{array}$ & $\begin{array}{l}7 \cdot 18 \\
(7 \cdot 00-7 \cdot 35) \\
7 \cdot 27 \\
(7 \cdot 18-7 \cdot 33) \\
<0 \cdot 025\end{array}$ & $\begin{array}{l}7 \cdot 22 \\
(7 \cdot 11-7 \cdot 33) \\
7 \cdot 28 \\
(7 \cdot 01-7 \cdot 41) \\
\text { NS }\end{array}$ \\
\hline $\begin{array}{l}\mathrm{PCO}_{2}(\mathrm{mmHg}) \\
\text { Haemorrhage } \\
\text { Non-haemorrhage } \\
\mathrm{P}\end{array}$ & $\begin{array}{l}63 \\
(38-141) \\
47 \\
(36-62) \\
<0.001\end{array}$ & $\begin{array}{l}62 \\
(41-110) \\
44 \\
(29-62) \\
<0 \cdot 001\end{array}$ & $\begin{array}{l}60 \\
(39-106) \\
46 \\
(33-77) \\
<0.01\end{array}$ & $\begin{array}{l}50 \\
(42-80) \\
44 \\
(31-65) \\
<0.01\end{array}$ & $\begin{array}{l}54 \\
(41-97) \\
43 \\
(36-52) \\
<0.001\end{array}$ & $\begin{array}{l}56 \\
(36-85) \\
44 \\
(32-92) \\
<0.01\end{array}$ & $\begin{array}{l}53 \\
(35-79) \\
44 \\
(29-78) \\
<0.01\end{array}$ \\
\hline $\begin{array}{l}\text { Base excess }(\mathrm{mmol} / \mathrm{l}) \\
\text { Haemorrhage } \\
\text { Non-haemorrhage } \\
\text { P }\end{array}$ & $\begin{array}{l}-9 \\
(-18-+1) \\
-4 \\
(-11-0) \\
<0.001\end{array}$ & $\begin{array}{l}-11 \\
(-25-+1) \\
-4 \\
(-10--1) \\
<0.001\end{array}$ & $\begin{array}{l}-10 \\
(-15--1) \\
-5 \\
(-14--3) \\
<0.01\end{array}$ & $\begin{array}{l}-9 \\
(-14-0) \\
-6 \\
(-11--3) \\
\text { NS }\end{array}$ & $\begin{array}{l}-8 \\
(-15--3) \\
-6 \\
(-14--2) \\
=0.05\end{array}$ & $\begin{array}{l}-7 \\
(-14--2) \\
-6 \\
(-10-0) \\
\text { NS }\end{array}$ & $\begin{array}{l}-8 \\
(-13-+5) \\
-5 \\
(-12--2) \\
\text { NS }\end{array}$ \\
\hline
\end{tabular}

surviving infants appeared neurologically normal at discharge, although only long-term follow-up will confirm this.

Because only infants of $<1500 \mathrm{~g}$ birthweight were studied, an association of PVH with prematurity and low birthweight ${ }^{7}$ was not observed. The principal differences between the $\mathrm{H}$ and $\mathrm{NH}$ groups concerned the occurrence of respiratory problems. Of the 23 infants developing symptoms of respiratory distress in the first 24 hours, 17 were found to have PVH $(\mathrm{P}=\mathbf{0} \cdot 0008)$. The requirement for inspired oxygen concentrations of $>60 \%$, and the arterial oxygen saturations measured were not significantly different during the first week. $\mathrm{H}$ babies were nevertheless significantly more acidotic during the first 6 days, with a greater degree of metabolic acidosis during the first 3 days, indicating that oxygen delivery to peripheral tissues was less adequate than the arterial oxygen saturations would suggest.

The most pronounced difference between the two groups is the $\mathrm{PCO}_{2}$ which remained significantly higher in $\mathrm{H}$ infants for the first 7 days. Since all of the haemorrhages had occurred by the end of the first week and probably most of them by between 24 and 72 hours, part of this difference could have been due to hypoventilation secondary to PVH. However, all the $\mathbf{H}$ infants had received ventilatory support of some kind by the end of the first week making the high $\mathrm{PCO}_{2}$ more likely to have been due to severe lung disease which the $\mathrm{H}$ infants clearly had, than simply central nervous system depression. Thus, hypercapnia is more likely to be an associated cause, than the result of PVH. The association between PVH and respiratory distress, in particular hyaline membrane disease, has been demonstrated in necropsy studies. ${ }^{89}$ Moriette et al. found that in studies at necropsy on infants with hyaline membrane disease, PVH was associated with hypothermia, metabolic acidosis, and respiratory assistance. ${ }^{10}$ Papile et al. however, in an in vivo study, ${ }^{2}$ found no association with any perinatal factors including respiratory assistance. Wigglesworth ${ }^{11}{ }^{12}$ has suggested that hypercapnia and acidosis, because of their known vasodilator effects, could be important in the pathophysiology of PVH. Experimental evidence with newborn goats has shown cerebral blood flow to be related independently of both hydrogen ion concentration and $\mathrm{PCO}_{2} \cdot{ }^{13}$ In newborn infants respiratory distress has been shown to be associated with high cerebral blood flow if hypercapnia and normal blood pressure are present, ${ }^{14}$ and that sudden variations in flow occur with apnoea. Lou et al. ${ }^{15}$ have also shown disturbed cerebral blood flow in newborn infants, in the form of low flow rates after 'asphyxia' when hypotension was present.

The demonstration in this study of a clear association of PVH with both metabolic acidosis and hypercapnia lends further support to their role in the causation of PVH. Greater attention to maintenance of normal acid/base balance and 
normocapnia in the first few hours and days of life may reduce the incidence of PVH in low birthweight infants.

I thank the medical and nursing staff of the Neonatal Unit, Sophia Children's Hospital, for allowing me to study patients under their care.

\section{References}

1 Krishnamoorthy K S, Fernandez R A, Momose K J, et al. Evaluation of neonatal intracranial hemorrhage by computerized tomography. Pediatrics 1977; 59: 165-72.

2 Papile L A, Burstein J, Burstein R, Koffler H. Incidence and evolution of subependymal and intraventricular hemorrhage: a study of infants with birthweights less than 1500 g. J Pediatr 1978; 92 : 529-34.

3 Pape K, Blackwell R J, Cusick G, et al. Ultrasound detection of brain damage in preterm infants. Lancet 1979 ; i: $1261-4$.

4 Cooke R W I. Ultrasound examination of neonatal heads. Lancet 1979 ; ii: 38.

5 Tsiantos A, Victorin L, Relier J P, et al. Intracranial hemorrhage in the prematurely born infant. $J$ Pediatr $1974 ; 85$ : 854-9.

${ }^{6}$ Emerson $\mathrm{P}$, Fujimura M, Howat $\mathrm{P}$, et al. Timing of intraventricular haemorrhage. Arch Dis Child 1977; 52: 183-7.

7 Fedrick J, Butler N R. Certain causes of neonatal death. II. Intraventricular haemorrhage. Biol Neonate 1970; 15: 257-90.

${ }^{8}$ Leech $\mathbf{R}$ W, Kohnen P. Subependymal and intraventricular hemorrhages in the newborn. Am J Pathol $1974 ; 77: 465-75$.
${ }^{9}$ Harcke H T, Jr, Naeye R L, Storch A, Blanc W A. Perinatal cerebral intraventricular hemorrhage. $J$ Pediatr 1972; 80: 37-42.

10 Moriette G, Relier J P, Larroche J C. Les hémorragies intra-ventriculaires au cours de la maladie des membranes hyalines. Arch Fr Pediatr 1977; 34: 492-504.

11 Hambleton G, Wigglesworth J S. Origin of intraventricular haemorrhage in the preterm infant. Arch Dis Child $1976 ; 51$ : 651-9.

12 Wigglesworth J S, Pape K E. An integrated model for haemorrhagic and ischaemic lesions in the newborn brain. Early Hum Dev 1978; 2: 179-99.

13 Bucciarelli R L, Eitzman D V. Cerebral blood flow during acute acidosis in perinatal goats. Pediatr Res 1979; 13: 178-80.

14 Cooke R W I, Rolfe P, Howat P. Apparent cerebral blood flow in newborns with respiratory disease. Dev Med Child Neurol 1979; 21 : 154-60.

15 Lou H L, Lassen N A, Friis-Hansen B. Low cerebral blood flow in hypotensive perinatal distress. Acta Neurol Scand 1977; 56: 343-52.

16 Harrison $\mathrm{V} C$, Heese $\mathrm{H}$ de $\mathrm{V}$, Klein $\mathrm{M}$. Intracranial haemorrhage associated with hyaline membrane disease. Arch Dis Child 1968; 43: 116-20.

17 Deonna T, Payot M, Probst A, Prod'hom L S. Neonatal intracranial hemorrhage in premature infants. Pediatrics 1975 ; 56: $1056-64$.

Correspondence to Dr R W I Cooke, Department of Child Health, Alder Hey Children's Hospital, Eaton Road, Liverpool L12 2AP.

Received 11 March 1980 